\title{
The Impact of Ethical Concerns on Fashion Consumerism: A Review
}

Lena Cavusoglu

Izmir University of Economics

Mourad Dakhli

Georgia State University

Follow this and additional works at: https://digitalcommons.uri.edu/mgdr

Part of the Business Law, Public Responsibility, and Ethics Commons, Fashion Business Commons, Gender and Sexuality Commons, International Business Commons, and the Marketing Commons

\section{Recommended Citation}

Cavusoglu, Lena and Dakhli, Mourad (2016) "The Impact of Ethical Concerns on Fashion Consumerism: A Review," Markets, Globalization \& Development Review. Vol. 1: No. 2, Article 5.

DOI: 10.23860/MGDR-2016-01-02-05

Available at: https://digitalcommons.uri.edu/mgdr/vol1/iss2/5

This Article is brought to you for free and open access by DigitalCommons@URI. It has been accepted for inclusion in Markets, Globalization \& Development Review by an authorized editor of DigitalCommons@URI. For more information, please contact digitalcommons-group@uri.edu. 


\section{The Impact of Ethical Concerns on Fashion Consumerism: A Review}

\section{Cover Page Footnote}

We would like to thank MDGR editors Nikhilesh Dholakia and Deniz Atik for their valuable guidance on this manuscript, which made its publication possible. 


\section{Markets, Globalization \& Development Review}
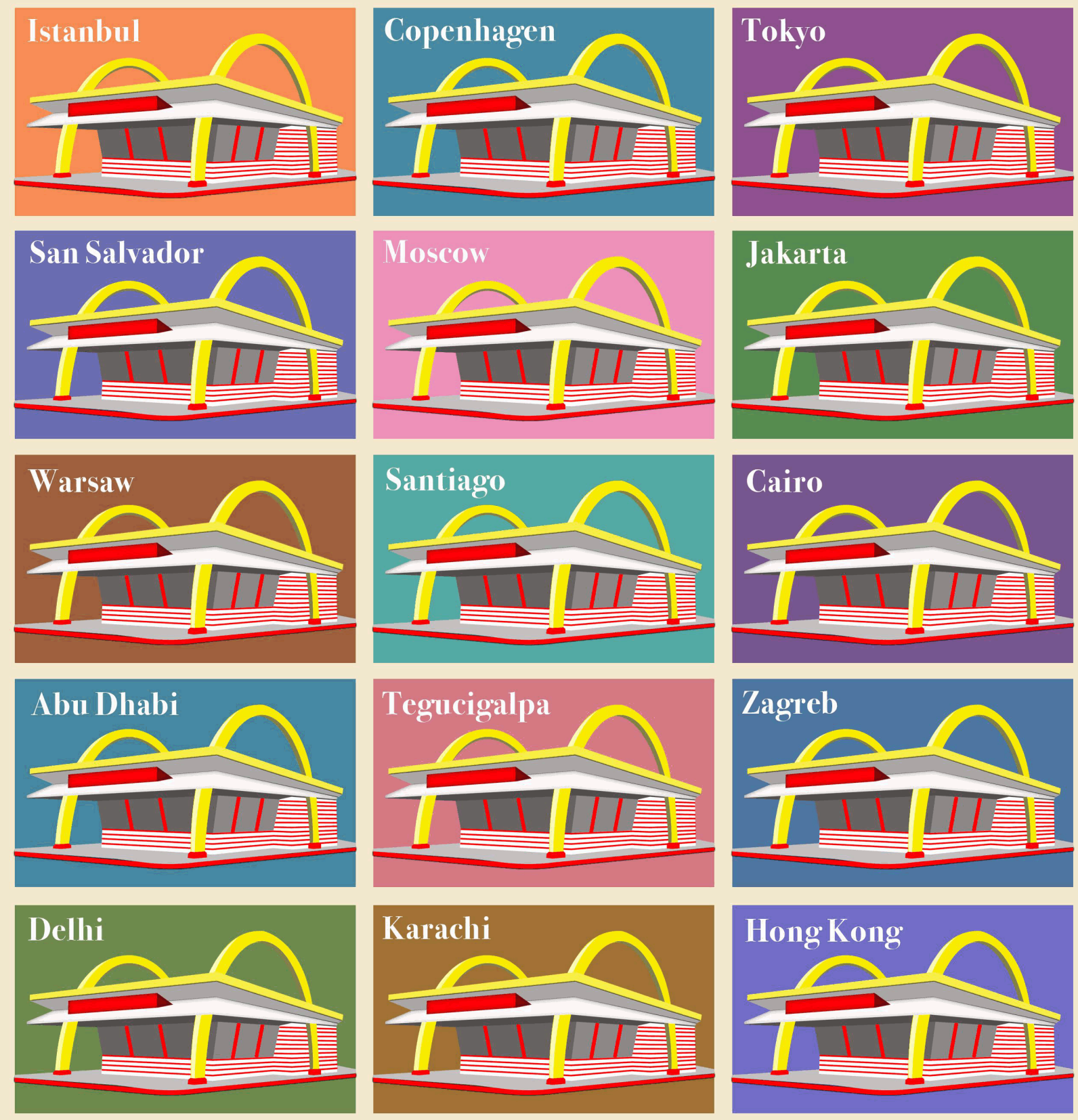

This article is available in Markets, Globalization \& Development Review: https://digitalcommons.uri.edu/mgdr/vol1/ 


\section{The Impact of Ethical Concerns on Fashion Consumerism: A Review}

\section{Introduction}

The fashion industry represents the meeting point of millions of people across the world, and is one of the leading industries that epitomizes the new globalized world of the 21st century (Hilary 2015). Fashion is, in fact, a phenomenon that affects various aspects of our lives, and studying the fashion system helps us understand contemporary culture, society, and consumers (Atik and Firat 2013; Ozdamar-Ertekin 2016). In conjunction with the globalization of societies, culture, and capital, both consumer markets and production systems in the fashion industry are highly globalized (Dholakia and Atik 2016). As a result, today more than ever, ethics is seen as one of the biggest concerns. Fashion companies are regularly involved with various ethical issues, and such companies are often entangled in ethical dilemmas and debacles with serious implications on an array of tangible and intangible performance indicators (Paulins and Hillery 2009).

The dizzying speed of fashion consumption and production affects the environment and the natural resources negatively, and may involve exploitation of labor, encouraging materialism, and promoting unnecessary consumption, among other concerns (Ozdamar-Ertekin 2016). Philanthropists, environmentalists, human and animal rights activists, and conscious consumers all around the world have been engaged in increasingly active protests against the apparent unethical practices in the fashion industry. Therefore, we believe it is critical to investigate the challenges and opportunities of ethical concerns in the fashion industry, and identify best practices so as to encourage progress and support the development of a peaceful and fairer world via responsible fashion approaches. We have undertaken a large and long-term project to identify problematic as well as best practices, and this paper is a first report from our work.

Business and marketing ethics in the fashion industry are drawing the growing attention of various researchers across diverse disciplines. Ethics have been studied in numerous business aspects including branding (e.g., Bin et al. 2012; Fan 2005). A practitioner, Joergens (2006), defined ethical fashion, evaluated the awareness of ethical issues in the fashion industry, and analyzed the attitudes of consumers towards ethical fashion. Marketing scholars Cervellon and Wernerfelt (2012) argued that online communities with a strong consumer orientation are useful to build 
sustainable fashion supply chains and to spread knowledge among consumers. Jägel et al. (2012) have explored the relationships between desired consumption outcomes and personal values when purchasing ethical products. As interest in ethical practices in the fashion industry rises on both the suppliers and consumers side of the market, there is a growing need for research to better understand how ethical concerns are embedded in the fashion industry.

This paper is part of a larger research project wherein, through reallife anecdotes and records of high profile cases, we are examining why and how consumers react to instances of perceived unethical practices. We aim to contribute to the understanding of ethical marketing in the fashion industry and its effects on firms' financial performance and reputation. This initial paper from the larger explores, via a detailed literature review, the concept of ethical marketing in the global fashion industry and its link to corporate reputation and consumer reactions. We structure this review, the first output of work and a conceptual one, in multiple categories that have been considered relevant in literatures on sustainability, fashion, and business ethics. In the end, we offer short conclusions and some comments to set the stage for presenting further evidence, empirically based examples and reports, from our larger project on the ethical aspects of the global fashion system.

\section{General Theoretical Background}

Adhering to strict ethical and sustainable practices has become a major concern in the fashion industry as consumers' demands today are no longer limited to purchasing high-quality products but also cover corporate social responsibility and sustainability (Emberley 1998; Joy et al. 2012; Moisander and Personen 2002). Here, sustainability is defined as the ability "to meet the needs of the present without compromising the ability of future generations to meet their own needs" (Brundtland Report, 1987; see also Kumar and Bhaskar 2016). Consequently, we treat sustainability in this paper as covering both social and environmental concerns.

Williamson (1978, p. 13) noted that "people are made to identify themselves with what they consume". Thus, for conscious consumers, there is a growing expectation related to a company's ethical conduct and social responsibility. For example, a 2012 Ethical Consumerism Report revealed that $42 \%$ of UK-based consumers bought primarily for ethical reasons in 2012 as compared to $27 \%$ in 2000 . In addition, $50 \%$ of consumers polled reported that they refrain from purchase of product and service on the basis of a company's ethical reputation, an increase from 44\% in 2000 (The Co-operative Group 2012). This supports previous 
research that showed that the ethical culture of a company affects the behavior of its consumers (Hall 1999). According to the author, when purchasing, two-thirds of the consumers consider a company's ethical stance, in terms of statements as well as actions, while 7\% stated that if a company is perceived as being involved in unethical practices, it would adversely impact their purchase decision. Consumers, it seems, have become increasingly interested in accessing reliable information about the background of the products they buy as they seek to align their purchase behavior with their ethical convictions (Alexander and Nicholls 2006; Boulstridge and Carrigan 2000). Furthermore, increasingly consumers are showing a greater level of concern with firms' supply chain activities demanding greater transparency and honest communication by firms in order to be more thorough and informed about their decisions (Simon 1995).

As stated above, the adverse reaction of consumers against a company's unethical practices is increasing in the fashion industry because of the global nature of the industry, and its direct association with a wide array of environmental and human rights issues (McCartney 2015). Some of these are environment related (e.g., green fashion and cruelty to animals), human rights related (e.g., fair labor practices, sweatshops, child labor), body image related with displays of idealized but in general unattainable body images, or culture and social values related (e.g., charitable contributions). All of the concerns listed above have been shown to be associated with shopping decisions in the apparel retail industry based on the results of the Ryan Partnership Chicago/Mambo Sprouts Survey (2012). This large study found that over $60 \%$ of consumers cared about eco-sustainable features such as treatment of animals, about $43 \%$ cared about green production, 56\% cared about ethical and fair labor practices, $47 \%$ about earth-friendly and organic materials, and $20 \%$ stated that charitable contributions mattered most in driving their purchase behavior.

Below, we discuss selected cases of ethical fashion challenges organized by ethics domain. We focus on environmental and social wellbeing concerns.

\section{Environmental Wellbeing}

The relationship between people and the environment is one of the central concerns of ethical fashion (Lu 2014). Joergens defined ethical fashion as "fashionable clothes that incorporate fair trade principles with sweatshopfree labor conditions while not harming the environment or workers by using biodegradable and organic cotton" (2006, p. 361). Similarly, Ethical 
Fashion Forum (n.d) defined ethical fashion as "an approach to the design, sourcing and manufacture of clothing which maximizes benefits to people and communities while minimizing impact on the environment."

Environmental concerns include any hazardous impact of the fashion industry on the world by "being the second largest polluter of the planet after oil" (Morgan 2015). The large volumes of clothing production lead to higher disposal rates, and consequently high levels of waste, which in turn exasperates the challenge of scarcity of natural resources (Ozdamar-Ertekin 2016). In addition, the current speed of fashion systems encourages consumers to buy lower-quality clothing made of artificial fibers and harmful dyes that have significant negative environmental footprints (Goodwin 2012). Recently, consumers have increasingly been supporting retailers and manufacturers that employ environmentally friendly or green practices (Kent 2007-2008). Eco-fashion is in fact a rising trend among consumers, firms, and researchers alike (Beard 2008). For example, Niinimäki (2010), studied eco-fashion consumption and found consumers' purchase decisions to be associated with the construction of self and how it relates to external symbols such as appearance, clothing and fashion accessories. Sociologist Aspers (2008) proposed an ethical and environmental labeling systems for the apparel industry that provide information about the ethical stance of the product as to allow consumers to make an informed decision about whether they are willing to pay more to support fashion industry workers or other environmental and charitable organizations. Ethical concerns have become so important that according to a survey conducted by Cohn \& Wolfe (2010), over $60 \%$ of consumers want to buy from environmentally responsible companies, and over $30 \%$ of consumers plan to spend more on green products. In addition, seven in ten $(69 \%)$ shoppers report that they consider eco/sustainability when buying apparel, with only three in ten claiming that they rarely $(23 \%)$ or do not consider $(7 \%)$ this factor when making their apparel purchase decisions (Ryan Partnership Chicago/Mambo Sprouts Marketing 2012). As a result, fashion brands are becoming more environmentally conscious, for example seeking and using less harmful dyes and chemicals in their production processes.

In addition to the environmental issues outlined above, the fashion industry has also been accused of animal rights violations, and of causing harm to many endangered species (PETA n.d.). Throughout history, animal-based materials such as wool, hides, fur, and leather have been used as clothing and accessories (Wilcox 1951). In today's fashion, fur and leather occupy an important role and are often regarded as luxury items that symbolize status (Stone 2008). Designers including Christian 
Dior, Yves Saint Laurent, and Karl Lagerfeld use real animal fur. The acquisition of this fur has been shown to be an inhumane process (Lee 2014). Animal rights advocates and conscientious consumers are becoming more vocal and aggressive against the use of fur and leather in fashion clothing (Olson and Goodnight 1994). A study by Ajzen and Fishbein (1980, p. 5) noted that "people are quite rational and make systematic use of the information available to them." It is not surprising that campaigns about sustainable fashion and ethical treatment of animals affect purchase and consumption decisions of consumers, and create adverse reactions against brands that are following what may be considered as unethical practices in this area.

\section{Social Wellbeing}

Social concerns in the fashion industry include a wide array of factors that are underpayment of labor, violations of labor rights, child labor, as well as mental and physical health of the models to name a few. Social ethics concerns pertain to ensure the wellbeing of the people and communities behind the fashion industry (Ethical Fashion Forum n.d.). The alarming documentary "The True Cost" brought many of these issues to the forefront with its depiction of the workers around the world that make the clothes we wear every day, and the sweatshop conditions that characterize their daily work environment (Morgan 2015). Low wages, long hours, child labor and other forms of labor abuse have come under major scrutiny and have been condemned by a wide range of critics in the fashion industry (Arnold and Hartman 2006; McRobbie 1997).

Sweatshop labor in the garment industry has caused an international outcry, especially where employments in these sweatshops involves children (Cataldi et al. 2010). It is a common practice in these types of working conditions for work to be taken home where children can be put to work outside any formal government monitoring or control. In many cases, workers are frequently paid by the piece rather than paid a guaranteed hourly wage (Beder 2002). During the 1990s, anti-sweatshop activists - including scholars, college students, and non-profit organizations - to improve working conditions for employees in many developing countries (Harrison and Scors 2010). As a result of these pressures, wages at many factories operated by multinationals have risen (Lim 2001).

The sexual objectification of women's bodies in fashion advertisements is another major ethical concern that has received increasing attention in the past few years. In this case, women are often portrayed as an aesthetic object of desire for men (Ferguson, Kreshel and 
Tinkham 1990; Reichert et al. 1999). This practice of portraying the female body as a desirable object reinforces stereotypical gender roles and has serious negative consequences, especially in the way women experience their bodies (Tiggemann and McGill 2004). Collins (2011) for instance found that the average woman's body shape is under-represented while the sexualized body, or the representation of women as sexual objects, is overemphasized in fashion communication. A particularly disturbing aspect is the obsessive emphasis on thinness of the female figure, leading to severe eating disorders not only among the models but also among girls and young women who seek to emulate these models.

Advertising is a powerful tool that transfers the symbolic meaning that a brand possesses and builds a brand reputation (Fan 2005). A study by Chan et al. (2007) supports the notion that negative feelings towards an advertisement creates negative brand image, and subsequently decreases purchase intention. In support of this, Wayne, Deborah and Rik (2012) revealed that $47 \%$ of consumers would not buy a product if they find its ad offensive. Consumers experience positive reactions to a controversial ad if the content is seen as appropriate and representative of the product or service being advertised (Wayne, Deborah and Rik 2012). Therefore, it is important for firms in the fashion industry to understand how consumers respond to sexually-laden ads, and how culture, religion, and social norms affect consumers' responses (LaTour and Henthorne 1994).

A related issue that has also caused quite a bit of controversy is the use of photo-editing software, such as Photoshop, to enhance the appearance of female bodies. Prior research on the effects of such practices showed how exposure to these unrealistic and misleading representation of body images establishes unattainable beauty standards, leads to feelings of inadequacy, and jeopardizing self-esteem and psychological wellbeing of the people following such ads (Baker, Sivyer and Towell 1998; Botta 1999; Britton 2012).

Smolak (1996) noted that the absolute majority of models employed in the fashion industry were abnormally thin. The average woman in the U.S., for example, is 5'4" tall and weighs about 140 pounds while the average model is $5^{\prime} 11^{\prime \prime}$ tall and weighs 117 pounds. This means that the typical fashion model is in general skinnier than $98 \%$ of the average women (Smolak 1996). The depiction of an ultra-thin beauty ideal in advertising has been blamed for pushing up to 24 million Americans and 70 million individuals worldwide to eating disorders such as anorexia and bulimia. We cannot underemphasize how these practices have put women all over the world under immense stress, and have led to unhealthy teenage body image with serious subsequent physical and mental issues 
(The Renfrew Center Foundation for Eating Disorders 2002). Statistics from a study on dieting among pre-teens showed over half of nine and tenyear-old girls felt better if they were on a diet, and $81 \%$ of ten-year-olds were afraid of getting fat (Mellin, Irwin and Scully 1992). Interestingly, over half of the 18-to-25 year old women surveyed stated that they would prefer to be run over by a truck and two-thirds stated that they would prefer to be mean or stupid rather than to be fat (Gaesser 1996). Models themselves, while perceived as having perfect bodies, are also under strong pressures. The Model Alliance's industry survey (2012) reports that $68.3 \%$ of models around the world suffer from anxiety and depression, both serious mental health issues.

The fashion industry is not blind to the rise in the concern of the consumers, and to the mounting evidence associated with the portrayal of unrealistic body images and has taken numerous steps to remedy the situation (Beard 2008).

Among the newer and growing initiatives undertaken by key players in the fashion industry are the organization of various events and initiatives rooted in community development and improvement with the engagement of multiple stakeholders including the community members, leaders, and consumers (Paulins and Hillery 2009). Known as cause-related marketing, these programs often receive free publicity and have significant impact on brand recognition (Lev, Petrovits and Radhakrishnan 2010). Fashion companies are more keenly aware today of the relationship between participation in charitable causes, brand reputation, and financial return. One study found an average of $\$ 500,000$ increase in charitable contributions resulted in an estimated \$3 million increase in sales (Lev, Petrovits and Radhakrishnan 2010). It is therefore not surprising that charitable contributions by multinationals increased by $64 \%$ between 2010 and 2013 (Committee Encouraging Corporate Philanthropy 2013). The number of fashion companies that publish corporate social responsibility (CSR) reports highlighting their charitable contributions and other forms of community engagement increased significantly (Kozlowski, Bardecki and Searcy 2012).

\section{Concluding Comments}

Business around the world is a human and social activity and, like other similar domains of major human activities, it is likely to continue to be assessed from a moral standpoint (Robin and Reidenbach 1987). Branding, advertising, and supply chain management that are integral parts of marketing practices - in terms of moral scrutiny - are no exception. A brand itself is neither good nor bad, but the value a brand 
represents, and the branding decisions and practices the company adopts can be ethical or unethical. As such, the way a firm communicates about its brand, and the manner in which it behaves as a social actor with multiple stakeholders, can make the difference between failure and success.

In this paper, the first of a larger study, we discussed the positive and negative impacts of ethical marketing practices on consumers of fashion and fashion companies. Our review shows that, based on existing research, an ethical brand enhances the firm's reputation, and this, in turn, reinforces the brand and its performance in the global marketplace.

The review is a first step in a research process - not an episodic but a continuous one - that keeps exploring the ethical practices of fashion firms, and the interactions that occur between firms, their consumers and other stakeholders. Our own forthcoming work will present empirical evidence about these practices and interactions; and provide stepping stones for additional research of this type. 


\section{References}

Ajzen, I. and Fishbein, M. (1980), Understanding attitudes and predicting behavior. New Jersey: Prentice Hall.

Alexander, A. and Nicholls, A. (2006), "Rediscovering consumer-producer involvement: A network perspective on fair trade marketing", European Journal of Marketing, 40 (11/12), 1236-1253.

Arnold, D. and Hartman, L. (2006), "Worker rights and low wage industrialization: how to avoid sweathops", Human Rights Quarterly, 28 (3), 676-700.

Aspers, P. (2008), "Labelling fashion markets", International Journal of Consumer Studies, 32, 633-638.

Atik, D. and Firat, F. A. (2013), "Fashion Creation and Diffusion: The Institution of Marketing", Journal of Marketing Management, 29 (78), 836-860.

Baker, D., Sivyer, R. and Towell, T. (1998), "Body image dissatisfaction and eating attitudes in visually impaired women", International Journal of Eating Disorders, 24 (3), 319-322.

Beard, F. K. (2008), Humor in the Advertising Business: Theory, Practice, and Wit. Lanham, Maryland, USA: Rowman and Littlefield Publishers.

Beard, N. D. (2008), "The Branding of Ethical Fashion and the Consumer: A Luxury Niche or Mass-market Reality?", Fashion Theory: The Journal of Dress, Body \& Culture, 12 (4), 447-468.

Beder, S. (2002), "Putting the Boot In", The Ecologist, 32 (3) (66-7), 24-28.

Botta, R. A. (1999), “Television images and adolescent girls' body image disturbance", Journal of Communication, 49, 22-41.

Boulstridge, E. and Carrigan, M. (2000), "Do consumers really care about corporate responsibility? Highlighting the attitude-behaviour gap, Journal of Communication Management, 4 (4), 355-368.

Britton, A. M. (2012), The Beauty Industry 's Influence on Women in Society, Honors Theses, Paper 86.

Brundtland Report (1987), "World Commission on Environment and Development: Our Common Future”, (accessed September 12, 2015), [available at http://www.tjsl.edu/slomansonb/11.2 Bruntland.docx] 
Cataldi, C., Maureen, D. and Crystal, G. (2010), Slow Fashion: Tailoring a Strategic Approach towards Sustainability. Karlskrona, Sweden: Blekinge Institute of Technology.

Cervellon, M.-C. and Wernerfelt, A.-S. (2012), "Knowledge sharing among green fashion communities online: Lessons for the sustainable supply chain", Journal of Fashion Marketing and Management: An International Journal, 16 (2), 176-192.

Chan, K., Li, L., Diehl, S. and Terlutter, R. (2007), "Consumers' response to offensive advertising: A cross cultural study", International Marketing Review, 24, 606-628.

Cohn \& Wolfe (2010), "ImagePower Green Brands Survey", (accessed October 21, 2016), [available at http://www.cohnwolfe.com/sites/default/files/whitepapers/2010 Gre enBrands USMedia.pdf]

Collins, R. L. (2011), "Content analysis of gender roles in media: Where are we now and where should we go?", Sex Roles, 64, 290-298.

Committee Encouraging Corporate Philanthropy (2013), "Giving in Numbers: 2014 Edition", (accessed November 18, 2015), [available at http://cecp.co/measurement/benchmarking-reports/giving-innumbers.html]

Dholakia, N. and Atik, D. (2016), "Markets, Globalization, Development: Charting the Intersections of Three Multipolar Concepts", Markets, Globalization \& Development Review, 1 (1), 1-16.

Emberley, V. (1998), Venus and Furs: The Cultural Politics of Fur. London: I. B. Tauris \& Co.

Ethical Fashion Forum. (n.d.), “What is Ethical Fashion?', (accessed November 29, 2016), [available at http://www.ethicalfashionforum.com/the-issues/ethical-fashion]

Fan, Y. (2005), "Ethical branding and corporate reputation", Corporate Communications: An International Journal, 10 (4), 341-350.

Ferguson, J. H., Kreshel, P. J. and Tinkham, S. F. (1990), "In the pages of Ms.: Sex role portrayals of women in advertising", Journal of Advertising, 19, 40-51.

Gaesser, G. A. (1996), Big Fat Lies: The Truth About Your Weight and Your Health, New York: Fawcett Columbine. 
Goodwin, L. (2012), "Launch of Valuing our Clothes Report", (accessed November 21, 2016), [available at http://www.wrap.org.uk/sites/files/wrap/Valuing\%20our\%20clothes \%20speech\%20Liz\%20Goodwin.pdf]

Hall, J. (1999), "Corporate ethics and the new commercial paradigm", Journal of Brand Management, 7 (1), 38-47.

Harrison, A. and Scors, J. (2010), "Multinationals and Anti-Sweatshop Activism", American Economic Review, 100 (1), 247-273.

Hilary, J. (2015), "Globalization", (accessed November 12, 2016), [available at The True Cost: http://truecostmovie.com/learnmore/human-rights/]

Jägel, T., Keeling, K. A., Reppel, A. and Gruber, T. (2012), "Individual values and motivational complexities in ethical clothing consumption: A means-end approach", Journal of Marketing Management, 28 (3-4), 373-396.

Joergens, C. (2006), "Ethical fashion: myth or future trend?", Journal of Fashion Marketing \& Management, 10 (3), 360-371.

Joy, A., Sherry, Jr, J. F., Venkatesh, A., Wang, J. and Chan , R. (2012), "Fast Fashion, Sustainability, and the Ethical Appeal of Luxury Brands", Fashion Theory, 16 (3), 273-296.

Kent, B. (2007-2008) "Innovation and the Organic Textile Processing", (accessed November 11, 2015), [available http://kennisbank.hva.nl/document/219293]

Kozlowski, A., Bardecki, M. and Searcy, C. (2012), "Environmental impacts in the fashion industry", Journal of Corporate Citizenship, 45, 16-36.

Kumar, Bipul, and Kalyan Bhaskar (2016), "Electronic Waste and Sustainability: Reflections on a Rising Global Challenge", Markets, Globalization \& Development Review, 1 (1), Article 5.

LaTour, M. S. and Henthorne, T. L. (1994), Ethical judgments of sexual appeals in print advertising. Journal of Advertising, 23, 81-90.

Lee, M. (2014), "The effects of product information on consumer attitudes and purchase intentions of fashion products made of fur, leather, and wool", Graduate Dissertation, Paper 13840. 
Lev, B., Petrovits, C., and Radhakrishnan, S. (2010), "Is Doing Good Good For You? How Corporate Charitable Contributions Enhance Revenue Growth", Strategic Management Journal, 182-200.

Lim, L. (2001). The globalization debate: Issuess and challenges. Geneva: International Labour Organisation.

Lu, M.-L. (2014), "Fashion and ethics, social responsibility and profit", (accessed November 02, 2016), [available at http://sds.parsons.edu/transdesign/seminar/fashion-and-ethicssocial-responsibility-and-profit/]

McCartney, S. (2015), "BoF in Conversation with Stella McCartney", (I. Amed, Interviewer), London: The Business of Fashion.

McRobbie, A. (1997), "A New Kind of Rag Trade", In J. B. Holt (Ed.), The Consumer Society Reader (pp. 433-445). New York, NY: The New Press.

Mellin, L., Irwin, C. and Scully, S. (1992), "Disordered eating characteristics in girls: A survey of middle class children", Journal of the American Dietetic Association, 851-853.

Moisander, J. and Personen, S. (2002), "Narratives of Sustainable Ways of Living: Constructing the Self and Others as a Green Consumer", Management Decision, 40 (4), 329-342.

Morgan, A. (Writer) and Morgan, A. (Director) (2015), The True Cost [Motion Picture]. USA.

Niinimäki, K. (2010), Eco-clothing, consumer identity and ideology. Sustainable Development, 18 (3), 150-162.

Nike, Inc. (2012-2013), "Sustainable Business Performance Summary".

Olson, K. M. and Goodnight, T. (1994), "Entanglements of consumption, cruelty, privacy, and fashion: The social controversy over fur", The Quarterly Journal of Speech, 80, 249-276.

Ozdamar-Ertekin, Z. (2016), "Conflicting Perspectives on Speed: Dynamics and Consequences of the Fast Fashion System", Markets, Globalization \& Development Review, 1 (1), Article 6.

Paulins, V. and Hillery, J. (2009). Ethics in the Fashion Industry. New York: Fairchild Books.

PETA (n.d.), "Inside the Fur Industry: Factory Farms", (accessed November 11, 2016), [available at 
http://www.peta.org/issues/animals-used-for-clothing/animals-usedclothing-factsheets/inside-fur-industry-factory-farms/]

Reichert, T., Lambiase, J., Morgan, S., Carstarphen, M. and Zavoina, S. 1999), "Cheesecake and beefcake: No matter how you slice it, sexual explicitness in advertising continues to increase", Journalism \& Mass Communication Quarterly, 76, 7-20.

Robin, D. and Reidenbach, R. (1987), "Social Responsibility, Ethics, and Marketing Strategy: Closing the Gap between Concept and Application", Journal of Marketing, 51 (1), 44-58.

Ryan Partnership $®$ Chicago/Mambo Sprouts $®$ Marketing. (2012), "Styling Sustainability consumer apparel survey”, (accessed December 3, 2016), [available at http://www.marketdynamics.info/uploads/7/2/5/4/7254872/stylingsu stainability.pdf]

Simon, F. (1995), "Global corporate philanthropy: a strategic framework", International Marketing Review, 12 (4), 20-37.

Smolak, L. (1996), Next Door Neighbors puppet guide book. National Eating Disorders Association.

Stone, E. (2008), The dynamics of fashion. (3. ed., Ed.) New York: Fairchild.

The Co-operative Group (2012), Ethical Consumer Markets Report 2012. (accessed October 13, 2015), [available at http://www.ethicalconsumer.org/portals/0/downloads/ethicalconsum er-marketsreport-2012.pdf]

The Model Alliance (2012), Industry Analysis Survey. (accessed October3, 2016), [available at http://modelalliance.org/industry-analysis]

The Renfrew Center Foundation for Eating Disorders (2002), "Eating Disorders 101 Guide: A Summary of Issues, Statistics and Resources", (accessed October 23, 2016), [available at http://www.renfrew.org]

Tiggemann, M. and McGill, B. (2004), "The role of social comparison in the effect of magazine advertisements on women's mood and body dissatisfaction", Journal of Social and Clinical Psychology, 23, 2344.

Wayne, D. H., Deborah, J. M. and Rik, P. (2012), Consumer Behavior. Mason, $\mathrm{OH}$, USA: South-Western Cengage Learning. 
Markets, Globalization \& Development Review, Vol. 1 [2016], No. 2, Art. 5

Wilcox, R. T. (1951), The mode in furs. New York: Charles Scribner's Sons. 